\title{
Cold Model Study of Mixing Time in Hybrid Process*
}

\author{
By D. N. GHOSH** and R. P. SINGH**
}

\begin{abstract}
Synopsis
Water model experiments have been conducted to determine the mixing time in hybrid process with five circular tuyere arrangements. Complete mixing time of water has been determined by tracer technique. It has been shown that bottom gas flow rate per tuyeres and tuyere arrangement do not have much effect on mixing time. On the other hand, the number of tuyeres has a pronounced effect. The mixing time in hybrid process with different tuyeres arrangement was found to be higher than L.D. model except in one case. It has been speculated that the metallurgical and operational improvement in hybrid process over L.D. is not dependent on the lower mixing time due to bottom gas injection alone.
\end{abstract}

Key words: model; hybrid; perfect mixing time; bottom gas.

\section{Introduction}

The remarkable success of Q-BOP has given vivid impression upon the following two points:

' Great effect of strong stirring force in a molten steel bath brought about by the bottom blown gas on the metallurgical characteristics and stable operations and higher working ratio of the bottom blowing converter than L.D.'

Thus all the metallurgical and operational advantages of Q-BOP process over L.D. have been attributed to the single factor, i.e., strong stirring action by the bottom gas which ensures efficient homogenization of the bath.

It can be said without any doubt that this finding has been instrumental in the mushrooming growth of a large number of hybrid processes that are available today. Some amount of $\mathrm{O}_{2}$ and/or other gases (nitrogen, argon, carbon dioxide, hydrocarbon, etc.) are blown from the bottom along with main top blown oxygen, to bring a distinct decrease in the mixing time. The fact that all these hybrid processes lie between the two limits of the top and bottom blowing is brought out in Fig. 1.1)

As it is shown in Fig. 1, the mixing time smoothly decreases with increasing amount of bottom gas although the processes were developed in different countries with different mode of blowing conditions, i.e., inert and/or oxygen, permeable element / tuyeres and their numbers. Almost in all the literature of hybrid process Fig. 1 is referred but not much of information is available.

An attempt has been made to throw some light on the above subject on the basis of cold model experiments.

\section{Experiments}

The experimental procedure and simulation conditions have been described elsewhere. ${ }^{2)}$ The mixing time was measured with a conductimetric probe located on one side of the vessel. The probe was employed to monitor local changes in the conductivity of water after $10 \mathrm{ml}$ of $20 \% \mathrm{KCl}$ solution was added as a pulse input on the other side of the vessel. The
Fig. 1.

Effect of bottom gas flow rate on time for perfect bath mixing.

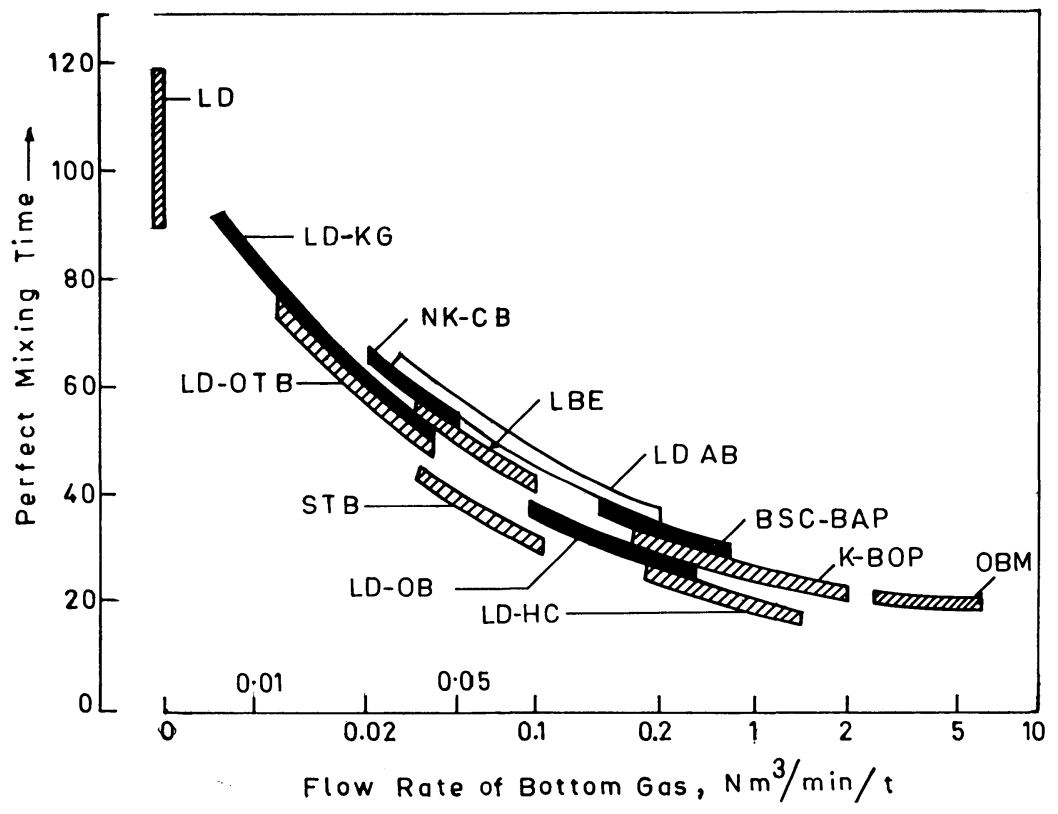

* Manuscript received on July 23, 1987; accepted in the final form on February 12, 1988. (C) 1988 ISIJ

** Department of Metallurgical Engineering, Indian Institute of Technology, Kharagpur 721302, India. 
probe was made of two platinum electrodes $(0.1 \mathrm{~cm}$ $\phi \times 1.0 \mathrm{~cm})$ separated by a distance of $1.0 \mathrm{~cm}$. Mixing time was defined as the time beyond which changes in the conductivity are less than $5 \%$ of the steadystate. The experiments per operating conditions were conducted and the mean value was taken as mixing time. The standard deviation of mixing time under any operating conditions was below $0.20 \mathrm{~s}$.

The nozzle used was three in number each having $1.0 \mathrm{~mm}$ I.D. and was tilted an angle of $12^{\circ}$ with lance axis. The lance was kept $6.0 \mathrm{~cm}$ from the still surface of water. The experiments was conducted by keeping top gas flow rate of $15 \mathrm{Nl} / \mathrm{min}$ and bath depth of $8.0 \mathrm{~cm}$. The bottom flow rates were 1,2 and $3 \mathrm{~N} l /$ min which is 6.6, 13.3 and $20 \%$ of the top gas. For bottom blowing, five (A, B, C, D, and E) tuyeres configuration was used (Fig. 5 on the top). The inner diameter of the tuyere was $1.0 \mathrm{~mm}$ each.

\section{Results}

\section{Effect of Amount of Bottom Gas}

The effect of amount of bottom gas at different tuyeres configuration is shown in Fig. 2. In general, it may be said that the perfect mixing time decreases with increasing amount of gas but the effect is not significant.

\section{Effect of Number and Configuration of Tuyeres}

The results show that tuyeres configurations $\mathrm{C}$ and $A(2)$ and $D$ and $B(5)$ have no significant effect on the perfect mixing time (Fig. 3). On the other hand, number of tuyeres has a significant effect on the mixing time. The minimum time decreases sharply with increasing number of tuyeres (Fig. 4).

\section{Comparison with L.D. and Q-BOP Processes}

Figiure 5 shows the perfect mixing time of hybrid

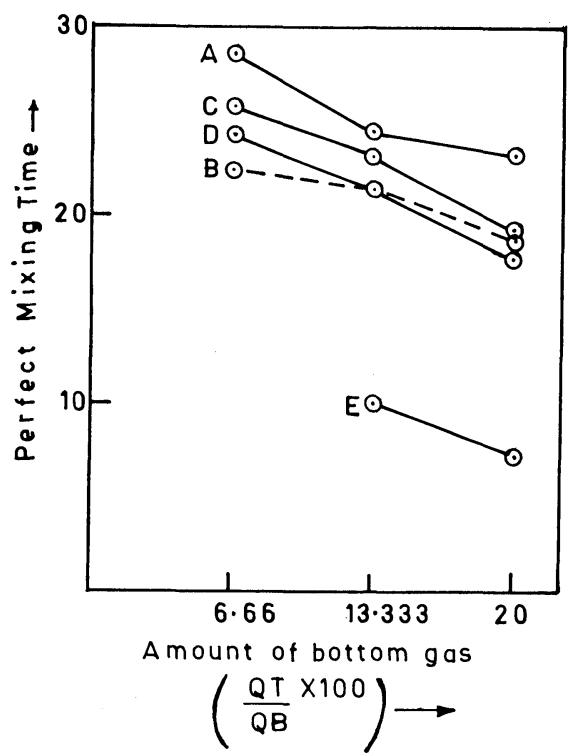

Fig. 2. Effect of amount of bottom gas $(\mathrm{QT} / \mathrm{QB} \times 100)$ on the perfect mixing time. process with different tuyeres configurations in comparison with L.D. and Q-BOP processes. It may be noted that the perfect mixing time with $\mathrm{A}, \mathrm{B}, \mathrm{C}$, and $\mathrm{D}$ configurations was higher than $\mathrm{LD}$ process under the different amount of bottom gas contrary to the findings of Fig. 5. Only with the E configuration, the mixing time was lower than L.D. process. Therefore, it may be said that the beneficial effect of bottom gas is not so straightforward as shown in Fig. 1.

\section{Discussion}

The influence of gas injection variables on the observed mixing time has been evaluated in term of stirring energy, $\epsilon_{t}$ imparted by the injected gas to the bulk liquid. The supply rate of stirring energy $\epsilon_{t}$ is shown by the equation as the sum to $\epsilon_{b}$ by the gas buoyancy and expansion and $\epsilon_{k}$ by the kinetic energy of the gas jet.

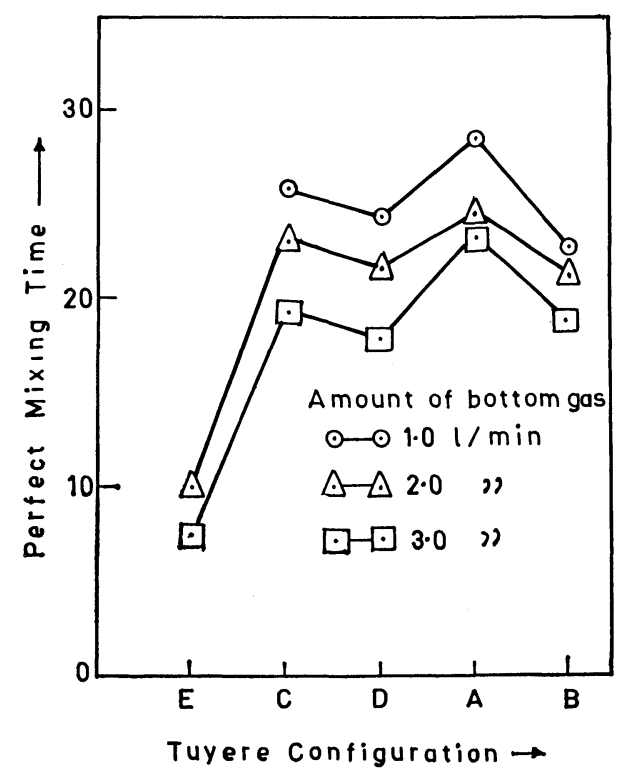

Fig. 3. Relationship between tuyeres configuration and perfect mixing time.

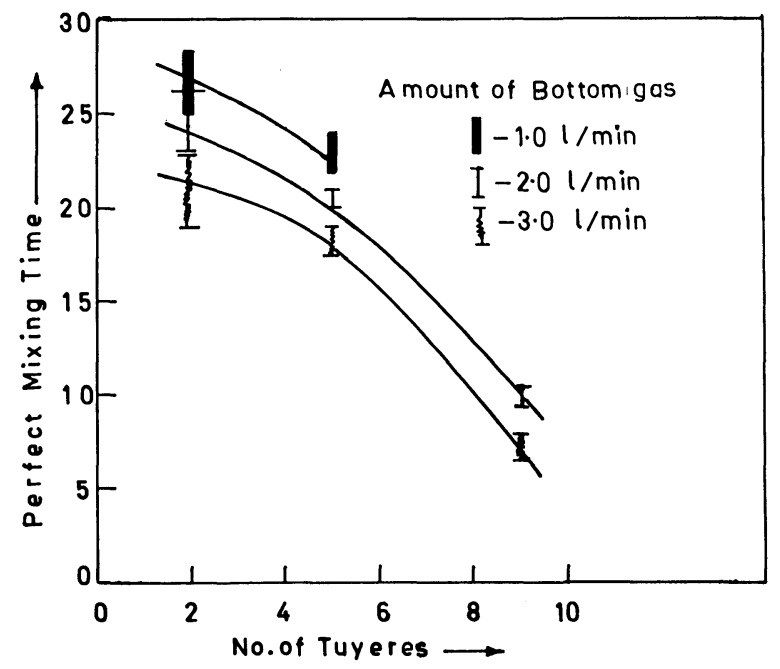

Fig. 4. Relationship between No. of tuyeres and the perfect mixing time. 


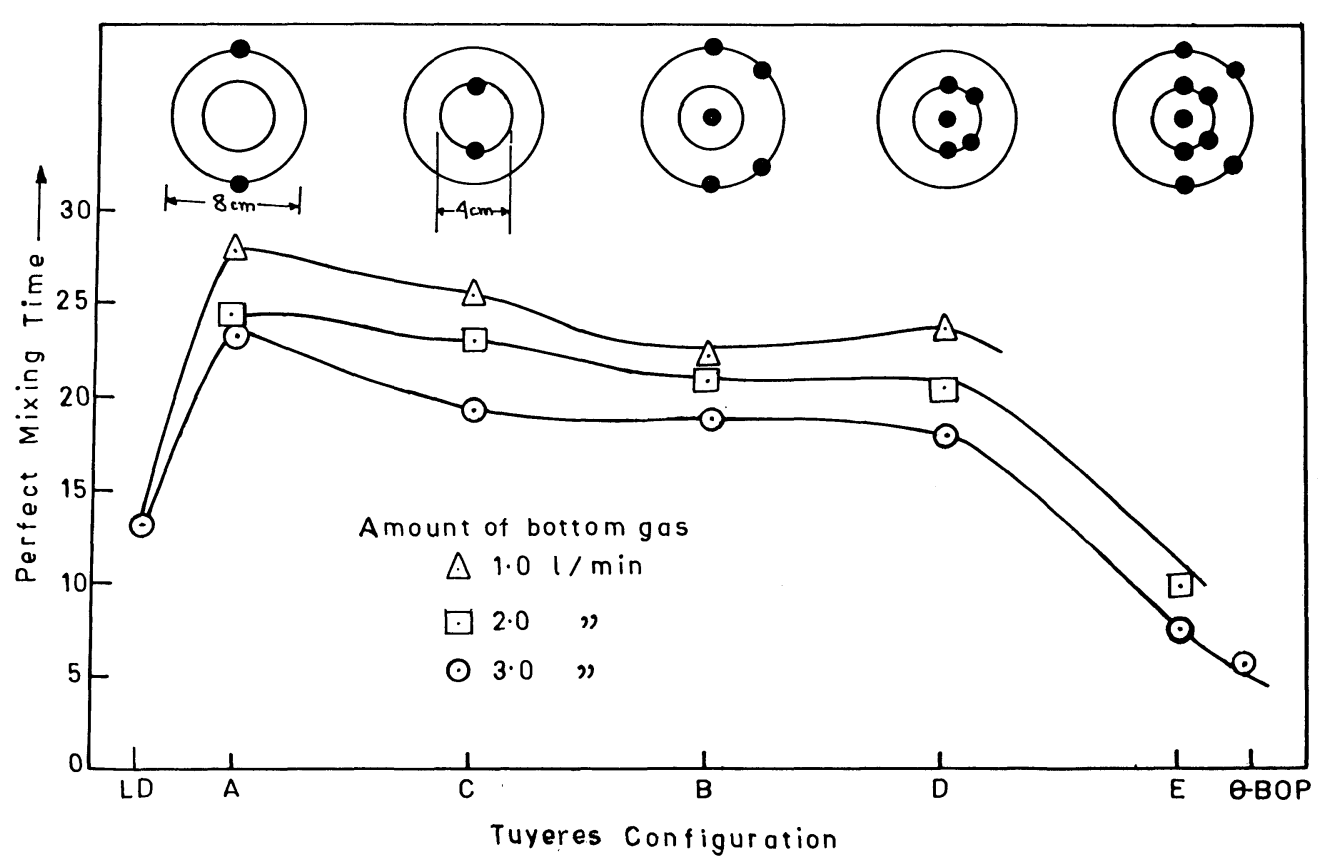

Fig. 5. Comparison of perfect mixing time of $\mathrm{LD}$ and $\mathrm{Q}-\mathrm{BOP}$ processes with hybrid processes of different tuyeres configuration.

$$
\begin{aligned}
\epsilon_{t}=\epsilon_{b}+\epsilon_{k}= & 0.0285 Q \cdot T / W_{g} \cdot \log \left(1+\frac{H}{1034}\right) \\
& +\frac{1}{2}\left(\rho_{g} u s\right) u^{2} / W_{g} \times 10^{-7} \ldots \ldots \ldots \ldots \ldots \ldots
\end{aligned}
$$

where, $Q$ : the gas flow rate $(\mathrm{N} l / \mathrm{min})$

T: the absolute temperature $\left({ }^{\circ} \mathrm{K}\right)$

$W_{g}$ : the weight of water $(\mathrm{t})$

$H:$ the bath depth $(\mathrm{cm})$

$\rho_{g}:$ the gas density $\left(\mathrm{g} / \mathrm{cm}^{3}\right)$

$S$ : the total cross-sectional area of tuyeres $\left(\mathrm{cm}^{2}\right)$

$u$ : the gas velocity at the outlet of nozzle $(\mathrm{cm} / \mathrm{s})$.

The values of $\epsilon_{b}$ and $\epsilon_{k}$ are shown in Table 1 under the present experimental conditions. The contribution of $\epsilon_{k}$ to the total energy is not much although it decreases appreciably with increasing number of tuyeres. It may be noted that the value of $\epsilon_{b}$ is governed by gas flow rate but the value of $\epsilon_{k}$ is strongly effected by both gas flow rate and number of tuyeres. Experimentally it has been concluded that the mixing time decreases quite appreciably with No. of tuyeres (Fig. 4), although $\epsilon_{k}$ does not contribute much to the mixing energy. ${ }^{3)}$ On the other hand, the value of $\epsilon_{b}$ increases quite appreciably with flow rate (Table 1), but the mixing time was not much effected by the flow rate (Fig. 2). Therefore, it may be said that the hybrid process with predominant top blowing the total mixing energy dissipated in the bath by bottom gas does not give any clear indication about the homogenisation of the bath.

The energy dissipated to the Q-BOP model with D configuration was calculated to be $644.3 \mathrm{~W} / \mathrm{t}$ water with $15 \mathrm{l} / \mathrm{min}$ of flow rate. The corresponding mixing time was $1.8 \mathrm{s.}^{2)}$ With the same flow rate, the

Table 1. Buoyancy and kinetic energy associated with bottom gas under different blowing conditions.

\begin{tabular}{cccccl}
\hline & & \multicolumn{4}{c}{$\epsilon_{k}(\mathrm{~W} / \mathrm{t}$-water $)$} \\
\cline { 4 - 6 } $\begin{array}{c}Q \\
(\mathrm{Ni} /\end{array}$ & $\begin{array}{c}H \\
\text { min })\end{array}$ & $(\mathrm{cm})$ & $(\mathrm{W} / \mathrm{t}$-water $)$ & \multicolumn{3}{c}{ No. of tuyeres } \\
\cline { 4 - 6 } & & & 2 & \multicolumn{1}{c}{5} & \multicolumn{1}{c}{9} \\
\hline 1 & 8 & 34.40 & 0.71 & 0.104 & 0.035 \\
2 & 8 & 68.84 & 5.58 & 0.832 & 0.28 \\
3 & 8 & 103.26 & 15.17 & 2.700 & 0.947 \\
\hline
\end{tabular}

mixing time for L.D. model was found to be $12 \mathrm{s.}^{2)}$ Inh ybrid model, with $1 \mathrm{l} / \mathrm{min}$ of bottom blow with the same D configuration, the total energy and the mixing time were found to be $34.4 \mathrm{~W} / \mathrm{t}$ water and $4.5 \mathrm{~s}$, respectively.

It seems unrealistic that the amount of bottom blown gas which is only about $5 \%$ of the Q-BOP value will be able to bring down the mixing time from 12 to $4.5 \mathrm{~s}$. While other configuration the mixing time was more than $12 \mathrm{~s}$ (Fig. 5). Therefore, it is not the amount of bottom gas but the flow pattern setup by the combined top and bottom blowing gas is important. The uniform distribution of bottom blowing gas with large number of tuyeres (Fig. 4) is more effective for better homogenisation.

It may therefore be said from the experimental result that lower mixing time is better degree of homogenisation should be achieved for the process using permeable plug / more number of tuyeres. But as it is shown in Fig. 1, the mixing time for above type of (LD-KG, LB-OTB, NK-OB, LBE) processes are higher than the other processes (STB, LD-OB, LDAC, K-BOP, NSS) using higher amount of bottom gas. It indicates therefore that the beneficial effect 
of hybrid process is not due to the lower mixing time alone as it is always referred to Fig. 1.

The $\% \mathrm{C}-\% \mathrm{O}$ relationship for some of the hybrid processes are shown in Fig. 6. $\mathrm{LBE}^{4)}$ process using permeable plug and inert gas flow rate of $0.17 \sim$ $0.25 \mathrm{NM}^{3} / \mathrm{min} / \mathrm{t}$, i.e. $6.7 \%$ of top blown amount. The K-BOP' ${ }^{5)}$ and $\mathrm{NSS}^{6)}$ processes use tuyeres ${ }^{2-4)}$ and $1.0 \sim 1.5 \mathrm{NM}^{3} / \mathrm{min} / \mathrm{t}$ of oxygen / neutral gas which is about $30 \%$ of the top gas. In spite of lower amount of bottom gas, $\% \mathrm{C} \times \% \mathrm{O}$ relation in $\mathrm{LBE}$ process is lower / same than the K-BOP and NSS processes. It also indicates that uniform distribution of bottom gas either by permeable plug or more number of small tuyeres helps to achieve better metallurgical results as it is shown in Fig. 6.

Small amount of neutral gas through the bottom definitely deliver lower amount of stirring energy, still better / same metallurgical effect is achieved (Fig. 6). Question arises 'Is really the mixing time alone as it is shown by Fig. 1 responsible for the metallurgical and operational improvement achieved in the hybrid process?'.

It appears that uniform distribution of bottom gas provides more number of nucleation sites for carbonoxidation reaction and due to enhance rate of $\mathrm{C}$ oxidation reaction brings out all other operational and metallurgical effect.

The following metallurgical observations reported in the literature supported the above speculation.

(1) The small gas bubbles injected in the bath create decarburization sites and if the gas is inert $\left(\mathrm{N}_{2}\right.$ or Ar) decrease the partial pressure of $\mathrm{CO}$, enhances the decarburization reaction further. ${ }^{4)}$

(2) ... with introduction of inert gas in LD of $0.03 \mathrm{NM}^{3} / \mathrm{min} / \mathrm{t}$ (i.e., $0.89 \%$ only of the top gas), the total iron level comes down to same as Q-BOP. ${ }^{7)}$

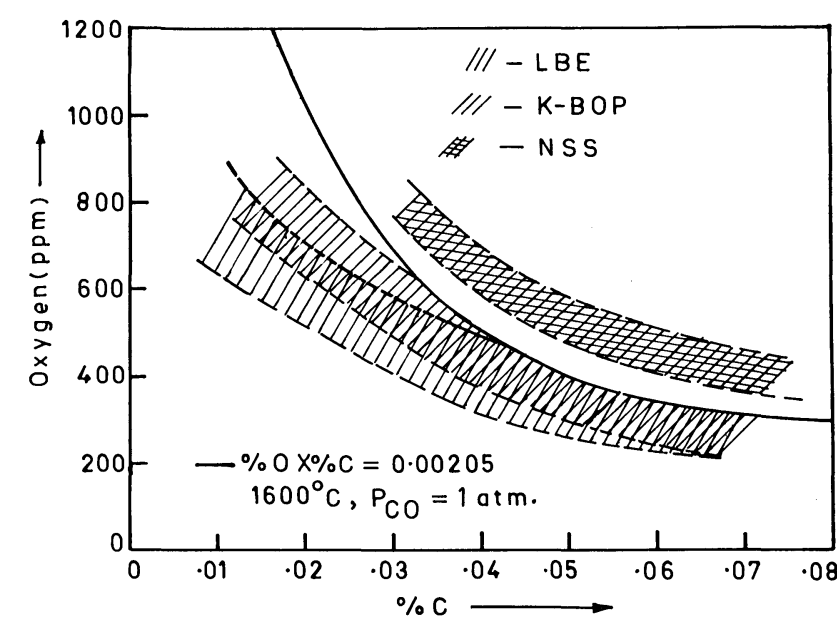

Fig. 6. Relationship between $\% \mathrm{G}$ and oxygen content for different hybrid processes.

\section{REFERENGES}

1) T. Emi: Stahl Eisen, 100 (1980), 998.

2) S. Paul and D. N. Ghosh: Metall. Trans. B., 17B (1986), 461.

3) O. Haida and J. K. Brimacombe: SCANINJEGT III, Part II, 3rd International Conference on Refining of Iron and Steel by Powder Injection, MEFOS-JERNKONTORET, Luleå, (1983), 5: 5 .

4) F. Schleimer, R. Henriean and F. Goedart: Proc. Int. Symp. on Modern Development in Steelmaking, Int. Steel Symp. Secretariat, Nat. Metall. Lab., Jamshedpur, (1981), 473.

5) T. Imai, K. Emoto and H. Ohmori: Fifth International Iron and Steel Congress, Steelmaking Proceedings, Vol. 69, ISS-AIME, Penn., (1986), 591.

6) H. Tukahasi, T. Okimura, F. Hashi and Y. Miyagawa: Steelmaking Proceedings, Vol. 69, ISS-AIME, Penn., (1986), 587.

7) Paul. E. Nilles: Proc. Int. Symp. on Modern Development in Steelmaking, Int. Steel Symp. Secretariat, Nat. Metall. Lab., Jamshedpur, (1987), 399. 